\title{
Country-level correlates of the Dark Triad traits in 49 countries
}

Peter K. Jonason $^{1,2}$ (i) | Magdalena Żemojtel-Piotrowska ${ }^{2}$ (i) | Jarosław Piotrowski ${ }^{2}$ |

Constantine Sedikides $^{3}$ ｜ W. Keith Campbell ${ }^{4}$ | Jochen E. Gebauer ${ }^{5,6}$ | John Maltby ${ }^{7}$ (D) |

Mladen Adamovic $^{8}$ | Byron G. Adams, ${ }^{90,11}$ | Anissa Lestari Kadiyono ${ }^{12}$

Kokou A. Atitsogbe ${ }^{13}$ | Harshalini Y. Bundhoo ${ }^{14}$ | Sergiu Bălțătescu ${ }^{15}$ | Snežana Bilić ${ }^{16}$ |

Joel Gruneau Brulin $^{17}$ | Phatthanakit Chobthamkit ${ }^{18}$ | Alejandra Del Carmen

Dominguez $^{19}$ | Sonya Dragova-Koleva ${ }^{20}$ | Sofián El-Astal ${ }^{21}$ | Carla Sofia Esteves ${ }^{22}$ |

Walaa Labib M. Eldesoki ${ }^{23,24}$ | Valdiney V. Gouveia ${ }^{25}$ | Katherine Gundolf $^{26}$ |

Dzintra Ilisko $^{27}$ | Emanuel Jauk ${ }^{28,29}$ | Shanmukh V. Kamble ${ }^{30}$ | Narine Khachatryan ${ }^{31}$ |

Martina Klicperova-Baker $^{32}$ | Emil Knezovic ${ }^{33}$ | Monika Kovacs $^{34}$ | Xuejun Lei ${ }^{35}$ |

Kadi Liik $^{36}$ | Agim Mamuti ${ }^{37}$ | Carlos Rodrigo Moreta-Herrera ${ }^{38}$ | Taciano L. Milfont ${ }^{39}$ |

Chin Wei Ong $^{40}$ | Evgeny Osin ${ }^{41}$ | Joonha Park ${ }^{42}$ | Boban Petrovic ${ }^{43 *}$ |

Jano Ramos-Diaz $^{44}$ | Goran Ridic ${ }^{33}$ | Abdul Qadir ${ }^{45}$ | Adil Samekin ${ }^{46}$ |

Artur Sawicki $^{47}$ | Habib Tiliouine ${ }^{48}$ | Robert Tomsik ${ }^{49}$ | Charles S. Umeh ${ }^{50}$ |

Kees van den Bos $^{51} \mid$ Alain Van Hiel ${ }^{10}$ | Osman Uslu ${ }^{52}$ | Anna Wlodarczyk ${ }^{53} \mid$ Illia Yahiiaev ${ }^{54}$

${ }^{1}$ University of Padova, Padua, Italy

${ }^{2}$ Cardinal Stefan Wyszyński University, Warsaw, Poland

${ }^{3}$ University of Southampton, Southampton, UK

${ }^{4}$ University of Georgia, Athens, GA, USA

${ }^{5}$ University of Mannheim, Mannheim, Germany

${ }^{6}$ University of Copenhagen, Copenhagen, Denmark

${ }^{7}$ University of Leicester, Leicester, UK

${ }^{8}$ Monash Business School, Monash University, Melbourne, Australia

${ }^{9}$ Tilburg University, Tilburg, The Netherlands

${ }^{10}$ Ghent University, Gent, Belgium

${ }^{11}$ University of Johannesburg, Johannesburg, South Africa

${ }^{12}$ Padjadjaran University, Bandung, Indonesia

${ }^{13}$ University of Lausanne, Lausanne, Switzerland

${ }^{14}$ University of Mauritius, Moka, Mauritius

${ }^{15}$ University of Oradea, Oradea, Romania

${ }^{16}$ International Balkan University, Skopje, North Macedonia

${ }^{17}$ Stockholm University, Stockholm, Sweden

${ }^{18}$ Thammasat University, Bangkok, Thailand

${ }^{19}$ Universidad Iberoamericana Ciudad de Mexico, Mexico, Mexico

${ }^{20}$ New Bulgarian University, Sofya, Bulgaria

${ }^{21}$ Al-Azhar University-Gaza, Gaza, Palestine

${ }^{22}$ Instituto Universitário de Lisboa (ISCTE-IUL), CIS-IUL, Lisboa, Portugal 


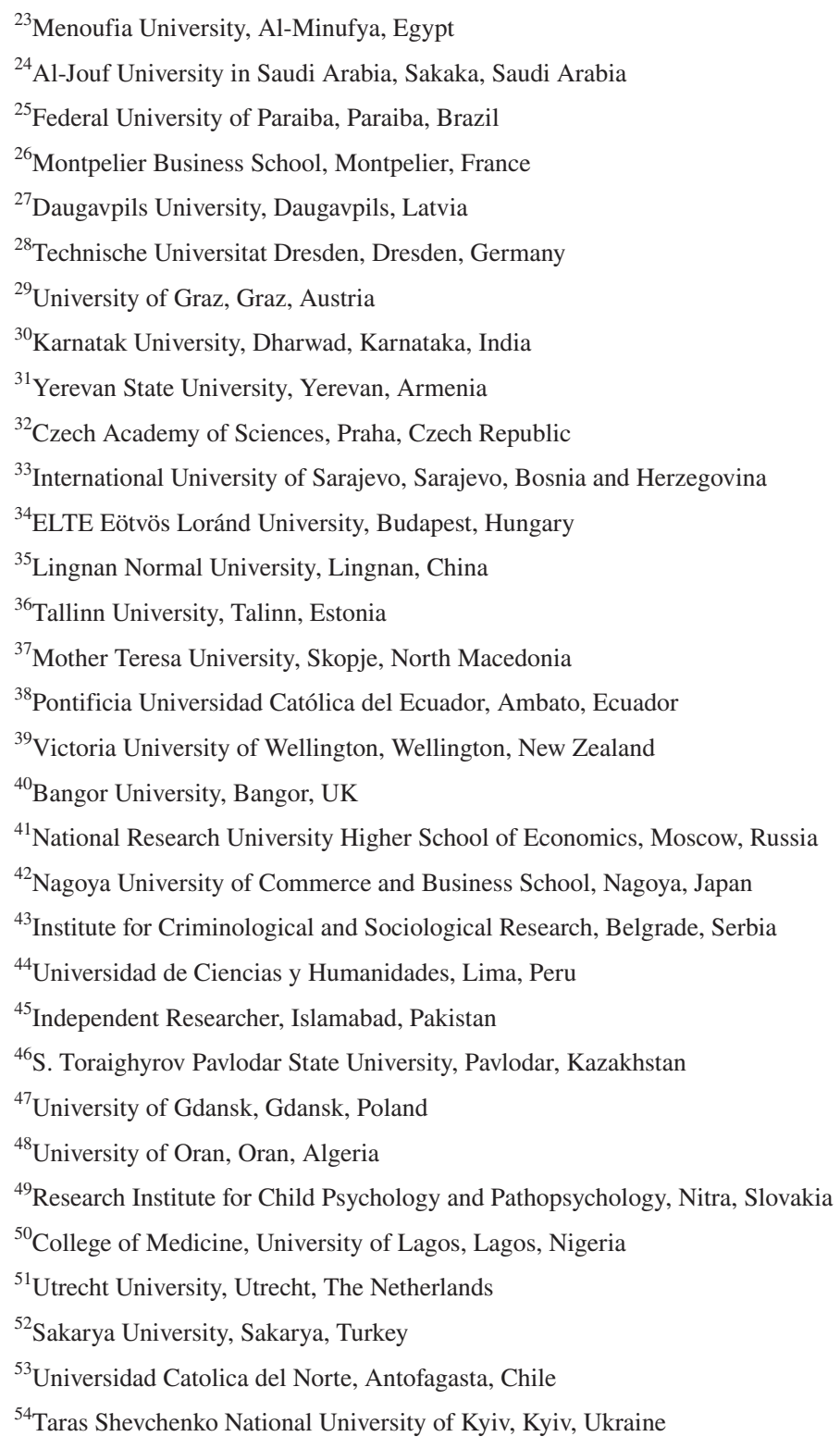

\section{Correspondence}

Magdalena Żemojtel-Piotrowska, Institute of Psychology, Cardinal Stefan Wyszyński University, Woycickiego 1/3 Street, 01-938 Warsaw, Poland.

Email: m.zemojtel-piotrowska@uksw. edu.pl

\section{Present address}

Taciano L. Milfont, The University of Waikato, Hamilton, New Zealand

\section{Funding information}

The Czech Academy of Sciences, Grant/ Award Number: RVO 68081740; Grantová Agentura České Republiky, Grant/Award Number: \#15-11062S; John Templeton

\begin{abstract}
Objectives: The Dark Triad traits (i.e., narcissism, psychopathy, Machiavellianism) capture individual differences in aversive personality to complement work on other taxonomies, such as the Big Five traits. However, the literature on the Dark Triad traits relies mostly on samples from English-speaking (i.e., Westernized) countries. We broadened the scope of this literature by sampling from a wider array of countries. Method: We drew on data from 49 countries $(N=11,723 ; 65.8 \%$ female; $A g e_{\text {Mean }}=21.53$ ) to examine how an extensive net of country-level variables in economic status (e.g., Human Development Index), social relations (e.g., gender equality), political orientations (e.g., democracy), and cultural values (e.g., embeddedness) relate to country-level rates of the Dark Triad traits, as well as variance in the magnitude of sex differences in them.
\end{abstract}


Foundation, Grant/Award Number: 51897; National Council of Technological and Scientific Development, Grant/ Award Number: n/a; Swiss Government Excellence PhD Scholarship, Grant/ Award Number: 2015.0639; Narodowe Centrum Nauki, Grant/Award Number: 2016/21/B/HS6/01069; Russian Academic Excellence, Grant/Award Number: 5-100; Polish National Agency for Academic Exchange, Grant/Award Number: PPN/ ULM/2019/1/00019/U/00001
Results: Narcissism was especially sensitive to country-level variables. Countries with more embedded and hierarchical cultural systems were more narcissistic. Also, sex differences in narcissism were larger in more developed societies: Women were less likely to be narcissistic in developed (vs. less developed) countries.

Conclusions: We discuss the results based on evolutionary and social role models of personality and sex differences. That higher country-level narcissism was more common in less developed countries, whereas sex differences in narcissism were larger in more developed countries, is more consistent with evolutionary than social role models.

\section{K E Y W O R D S}

cross-cultural, cultural values, Dark Triad, Machiavellianism, narcissism, psychopathy

\section{1 | INTRODUCTION}

Over the last 15 years, researchers have grown considerable interest in understanding three aversive personality traits, collectively known as the Dark Triad. The three traits are narcissism (i.e., grandiosity and self-centeredness), psychopathy (i.e., callous social attitudes and impulsivity), and Machiavellianism (i.e., manipulation and cynicism). However, most studies rely on relatively small samples from W.E.I.R.D. cultures (i.e., Western, educated, industrialized, rich, and democratic; Henrich, Heine, \& Norenzayan, 2010). Multinational studies have been conducted (Jonason et al., 2017; Jonason, Li, \& Czarna, 2013), but they sampled people from few countries and thus were unable to examine how country-level variance in the traits tracks with other country-level indicators (e.g., Human Development Index, Hierarchy values). In this study, we sampled people from 49 countries and examined mean-level differences as well as sex differences in the traits.

\subsection{Cultural differences in values}

Our primary concern was how countries and cultures differ in relation to the Dark Triad traits. They might differ in at least two ways. The first one entails sociopolitical factors. Countries vary in their development, corruption levels, freedom to engage in economic activities, adoption of democratic values, amount of internal strife, and the gender distribution of outcomes (Inglehart, Basanez, Diez-Madrano, Halman, \& Luijkx, 2004; Inglehart \& Norris, 2009). These factors represent a cross section of indicators encompassing social development, levels of political, and economic engagement, as well as the degree to which the internal workings of the countries are corrupt and tumultuous. As societies "advance" they create safer spaces, more equality, and less competition between citizens over scarce resources (Inglehart et al., 2004; Różycka-Tran, Boski, \& Wojciszke, 2015).

The second way in which countries differ entails shared values, with countries being loose approximations of cultures (Inglehart et al., 2004; Leung \& Bond, 2004; Schwartz, 2008). Countries differ in how much the collective population emphasizes values such as embeddedness, intellectual autonomy, affective autonomy, hierarchy, egalitarianism, mastery, and harmony (Schwartz, 2008). These cultural values may be responses to three societal problems: (1) how to handle relationships between individuals and the group, (2) how to maintain social order and how much order is desirable, and (3) how best to treat natural resources and the environment. The first societal problem is addressed by embeddedness versus autonomy (i.e., intellectual and affective) values. Cultures that value embeddedness emphasize collective identity, the status quo, social order, tradition, security, and obedience. Cultures that value intellectual autonomy emphasize broadmindedness, curiosity, and creativity in the guise of individuals pursuing their own ideas. Lastly, cultures that value affective autonomy emphasize people to pursue hedonism in the form of pleasure-seeking and having an exciting, varied life.

The second societal problem is addressed by hierarchy versus egalitarianism values. Cultures that can normatively be described as valuing hierarchy emphasize the legitimacy of asymmetries in power and the distribution of wealth, and thus endorse social power, authority, humility, and wealth. Cultures that value egalitarianism are socially progressive, care about the welfare of others, emphasize transcendence of 
individual or selfish interests, and underscore equality, social justice, responsibility, as well as honesty.

The third societal problem is addressed by mastery versus harmony values. Cultures that normatively value mastery emphasize getting ahead in the world by individual efforts and ambitiousness; these cultures are success-focused and daring. However, cultures that value harmony emphasize environmental concerns, a desire to live in-sync with nature as opposed to changing it, peace and unity, and wanting no more than one is owed from the world.

\section{2 | Personality $\times$ culture}

There are two main perspectives on how traits may differ across nations (Schmitt, Long, et al., 2017). First, personality traits may motivate individuals to behave in trait-consistent ways. Assuming many individuals in a culture have those traits, there should be a ratcheting-up from person-level patterns to country-level patterns. Social role theories (Eagly \& Wood, 1999) suggest that traits are learned patterns of behavior that are reinforced over time (i.e., behaviorism). These patterns would generalize out from person-level to countrylevel effects. In reference to the Dark Triad traits, such environmentally deterministic theories (e.g., social learning and media exposure theories) suggest that people are rewarded for being more aggressive and antisocial through modeling (e.g., classic Bobo doll experiments), which will lead to more negative externalities. However, such theories may overemphasize the role of learning, may only account for proximal mechanisms, may struggle to incorporate behavioral genetics or hormone research findings, and may view personality traits as fixed phenomena.

Second, personality traits may be adaptive responses to local contingencies (i.e., behavioral syndromes). Evolutionary researchers suggest that, although the aforementioned learning effects may occur, the reasons they occur are because of recurrent asymmetries in the payoffs for being socially antagonistic and that ontological variables calibrate preexisting mechanisms (Buss, 2009). From this view, traits like the Dark Triad might be adaptive responses to solve life history trade-offs that are generated by the interaction of dispositional biases and local contingencies (Figueredo et al., 2009). Put another way, traits are the outputs of heuristic processes that combine internal and external contingencies to optimize solving mating and survival challenges for a specific environment. Unlike social role theories, which view people as "victims" of external forces, evolutionary theories suggest that internal organizational (e.g., androgen during fetal development) and pubertal timing may create, for instance, sex differences in personality, or personality-environment matches through the active structuring of one's environment to suit their dispositions.
It is less clear, though, whether personality traits are created by or create these conditions. For example, the fact that beliefs in a zero-sum game (i.e., there are winners and losers in the world) are associated with country-level military expenditure in 30 countries (Różycka-Tran, Jurek, Olech, Piotrowski, \& Żemojtel-Piotrowska, 2019) could be interpreted as (1) people who hold those beliefs structure their society consistent with their personality, or (2) more violent societies elicit values as adaptive responses (i.e., in a dangerous place, zero-sum attitudes might be adaptive). Of the Dark Triad traits, narcissism is the most socially sensitive, as it is characterized by a need for external validation of one's identity through the attainment of status, dominance, and attractiveness (Sedikides \& Campbell, 2017). Therefore, if (some) traits are responses to local conditions, only the most socially sensitive traits should be correlated with country-level variance. Psychopathy, in particular, is relatively insensitive to environmental variance in behavioral genetics research (Vernon, Villani, Vickers, \& Harris, 2008). At the same time, all three of the Dark Triad traits have undesirable and antisocial implications (Muris, Merckelbach, Otgaar, \& Meijer, 2017). So, if there were a simple ratcheting-up to country-level detrimental effects, all three should be correlated with country-level factors such as less development, more corruption, and more within-country violence.

To understand how rates of the Dark Triad traits vary around the world, we gauged mean-level differences across 49 countries in relation to the aforementioned sociopolitical factors and the Schwartzian cultural values. At the person-level, the Dark Triad traits are considered malevolent (Muris et al., 2017), as they are associated with exploitive tendencies (Thomaes, Brummelman, \& Sedikides, 2018). If the Dark Triad traits facilitate person-level interpersonal strife, countries characterized by high levels of the Dark Triad traits would be characterized by strife, such as more internal conflicts and less gender equality.

Additionally, if personality traits are responses to local conditions, how should a trait like narcissism respond to different conditions? One hypothesis suggests that narcissism is created by a culture of indulgence or liberalization (Foster, Campbell, \& Twenge, 2003; Miller et al., 2015; Twenge \& Campbell, 2010), whereas an alternative view suggests that it might be created by scarcity (Campbell \& ŻemojtelPiotrowska, 2017; Papageorgiou et al., 2019). Regarding the latter view, in countries that are less developed, more corrupt, and have less economic freedom, peace, and gender equality, there is likely a greater degree of scarcity increasing competition for resources. Narcissism, as an agentic trait (Gebauer \& Sedikides, 2018), would enable people to compete over these scarce resources. That is, in "scarce" environments, being narcissistic may be adaptive, because it allows people to prioritize their own needs for facilitating their survival and reproductive goals (Jonason, Okan, \& Özsoy, 2019). In this 
case, external, country-level factors may necessitate an adaptive response in the form of a shortened personal timeline, limited investment in others, and general agentic behavior. Similarly, the cultural milieu created by different value systems may encourage people to respond. A more competitive value system (i.e., less egalitarianism and more hierarchy) and one that emphasizes community-connectedness (i.e., embeddedness) may create a space in which narcissism is a sensible response. Narcissistic individuals value social interaction and connection, but also status, prestige, and power (Mahadevan, Gregg, \& Sedikides, 2019). In fact, they value embeddedness as a means to gain status and power (i.e., to climb the hierarchy). After all, if one desires adoration, one needs to belong to an adoring group, and appear to promote the values and interests of that group. Therefore, rates of narcissism in countries should correlate with cultural emphasis on embeddedness and hierarchy (Schwartz, 2008).

\section{3 | Personality $\times$ culture $\times$ sex}

In North American, Western European, Eastern European, and South American samples, men are more narcissistic, psychopathic, and Machiavellian than women are, whereas in Asian (i.e., Singaporean and Japanese) and Turkish samples men are descriptively, but not statistically, better characterized by those traits as well (Jonason et al., 2013, 2017). As with mean-level differences, social role theories (e.g., structural powerlessness theory) suggest that sex differences are created by the presence of inequalities in one's local culture (Eagly \& Wood, 1999). If true, societies with more gender equality should have smaller sex differences. In contrast, evolutionary theories (e.g., antagonistic co-evolution) propose that, because ancestral men have suffered fewer physical and social costs for being antisocial and may even have gained positive fitness returns in the form of more sex partners relative to women (Carter, Lyons, \& Brewer, 2018), the sexes may have diverged accordingly. Evolutionary models predict that more gender equality will be associated with larger sex differences. The limited work on cross-cultural variance in sex differences in the Dark Triad (Neumann, Schmitt, Carter, Embley, \& Hare, 2012; Schmitt, Alcalay, et al., 2017) and the Big Five (i.e., Extraversion, Neuroticism, Agreeableness, Openness, Conscientiousness) traits (Giolla \& Kajonius, 2019) is more consistent with the latter class of theories. In addition, sex differences in prioritizing risk, patience, altruism, positive and negative reciprocity, and trust are larger in societies that are more liberal, are characterized by higher income, and have greater gender equality (Falk \& Hermle, 2018).

Women and men may be better able to maximize the expression of their personality in more advanced and liberal (e.g., more democratic) cultures than in less liberal (e.g., low gender equality) ones, because of social, legal, political, and religious constraints (Inglehart \& Norris, 2009). In socio-politically progressive and more advanced societies, the need for women to engage in antisocial or selfish behavior and, therefore, have the traits that would facilitate these behaviors, may be diminished. Although narcissism may help both women and men to gain resources in competitive spaces, its utility may be sensitive to local socioecological or cultural conditions. In harsher cultures, women-who evolutionarily need resources for themselves and their offspring more than men do-may need to augment the investment they receive from men to secure better provisions for themselves and their offspring. It follows that narcissism in women may act as an emergency system, whereas in men it may be a default system given that men reliably need access to resources to attract a partner, invest in offspring (albeit less so than women), and provide for their own survival (Kenrick, Sadalla, Groth, \& Trost, 1990). Therefore, whereas narcissism rates should be lower in more socio-politically advanced cultures (consistent with the scarcity hypothesis), it is women, more than men, who will be lower in narcissism in these cultures.

\section{4 | Overview}

In this multinational collaboration, we present the first largescale examination of cross-cultural variance in the Dark Triad traits. We use country-level sociological, economic, political, and cultural variables to account for variance in mean levels of the traits along with sex differences. Specifically, in relation to distribution of three "dark" traits around the world, we test whether they serve as adaptations to scarce resources, conflicted and unstable societies, and cultural factors related to competitiveness. We expect narcissism to be the most sensitive to country-level effects, but also explore the sensitivity of psychopathy and Machiavellianism. We compare scarcity and liberalization hypotheses to account for variance in the Dark Triad traits across countries. In relation to sex differences, we similarly examine scarcity and liberalization hypotheses, suggesting larger and smaller, respectively, sex differences in more affluent and egalitarian societies.

\section{2 | METHOD}

\section{1 | Participants and procedure}

The reported data $(N=11,723)$ were collected between April 2016 and October 2017 as part of the "Cross-Cultural SelfEnhancement Project" (led by the second and third authors), ${ }^{1}$ which brought together over 70 academics from 56 countries. For reasons described next, we included data from only 49 countries in the present study. A researcher from each 
sampled country was asked to recruit at least 150 participants (but ideally 250) for inclusion in the project so as to maximize power for detecting the average effect in social-personality psychology over the last 100 years (i.e., $r \approx .20$; Richard, Bond, \& Stokes-Zoota, 2003). Additionally, we attempted to include at least 50 participants per sex; we obtained a sample that was $66 \%$ female. We excluded countries with fewer than 150 participants, and countries where we did not assess the Dark Triad traits.

Table 1 contains a summary of the samples and procedure for each country. The sample consisted of moderately affluent (self-reported SES: $1=$ poor, $7=$ wealthy; $M=4.47$, $S D=1.10)$ university students $\left(\right.$ Mean $_{\text {Age }}=21.53$ years, $S D_{\text {Age }}=3.17$ years), $39 \%$ of whom took the survey in a paper-and-pencil form. Participants completed the study in their countries' official language. We used published translations where available and, when such translations were not available, we implemented standard back-translation procedures. We obtained informed consent in each country and debriefed participants upon completion. The project was reviewed and approved by the Ethics Committee of the former home institution of the first author (H14099) and the former home institution of the second and third authors (UG1/2016); reciprocal approval was secured elsewhere.

We assessed the Dark Triad traits using the Dirty Dozen (Jonason \& Webster, 2010). The 12 items were translated into each language by two native speakers, back translated by a third, and then, checked by the scale's first author. Particular translations can be obtained online (https://tinyurl.com/ wno77f2). Participants were asked how much they agreed $(1=$ not at all, $5=$ very $m u c h)$ with statements such as "I tend to want others to admire me" (i.e., narcissism), "I tend to lack remorse," (i.e., psychopathy) and "I have used deceit or lied to get my way" (i.e., Machiavellianism). We averaged responses to create indices of each trait. Overall, the traits evinced adequate-to-good internal consistency for narcis$\operatorname{sism}(\ddot{\alpha}=.85)$, Machiavellianism $(\stackrel{\|}{\alpha}=.84)$, and psychopathy

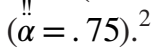

\section{2 | Country-level indicators}

All country-level sociopolitical indices that we report refer to 2017, corresponding with the approximate time of data collection. We used the Human Development Index (HDI), which was created for the Human Development Report prepared by the United Nations. ${ }^{3}$ HDI features three main components: a decent standard of living (GNI per capita in U.S. dollars; GNI index), knowledge (mean years of schooling; expected years of schooling), and a long and healthy life (life expectancy index; life expectancy at birth). The higher the score $(0-1)$, the greater level of human development a society has.
We measured the functioning of democracy with The Democracy Index created by The Economist Intelligence Unit. ${ }^{4}$ It encompasses 60 indicators with five categories: electoral process and pluralism, civil liberties, the functioning of government, political participation, political culture. Based on their scores on 60 indicators within these categories, each country is classified as one of four types of regimes: full democracy, flawed democracy, hybrid regime, authoritarian regime. The higher the score (1-10), the more democratic the society is.

We measured economic functioning with The Index of Economic Freedom, developed by The Heritage Foundation. It consists of 12 estimators of various fields of freedom, including property rights and financial freedom. ${ }^{5}$ The higher the score (0-100), the more economic freedom within a society.

We measured the relative position of women and men in society with The Gender Inequality Index. It is an assessment of gender inequality developed by the United Nations as part of the Human Development Report. ${ }^{6}$ The index is based on three domains: (1) reproductive health, gauged by maternal mortality ratio and adolescent birth rates, (2) empowerment, gauged by the proportion of parliamentary seats occupied by women and the proportion of adult women and men aged $25+$ years with at least some secondary education, and (3) economic status, gauged by labor force participation rates of men and women aged $15+$ years. The higher the value ( 0 to 1 ), the more gender inequality and disparities between the sexes.

We measured number of conflicts within a given society using The Global Peace Index. ${ }^{7}$ Created by The Institute for Economics and Peace (IEP), it assesses global peace with 23 indicators constituting three domains: level of societal safety and security, extent of ongoing domestic and international conflict, and degree of militarization. The higher the value (1 to 5), the more conflict-ridden a country is.

We measured income inequalities within society with The Gini Index from the C.I.A. World Factbook. ${ }^{8}$ A higher Gini score indicates greater inequality, with high-income individuals receiving a larger proportion of the country's total income. The index represents economic discrepancies among members of countries: $0=$ maximum equality (when income is perfectly divided among all members of a country), $100=$ maximum inequality (when one individual possesses all the money within a country).

We included Schwartz's (2008) cultural values of embeddedness, intellectual autonomy, affective autonomy, egalitarianism, hierarchy, mastery, and harmony. We obtained scores directly from Shalom Schwartz (personal communication, April 6, 2014), and supplemented them by data from Żemojtel-Piotrowska et al. (2014). We calculated supplemented data based on student samples, where we used the same methodology as for normative data 
T A B L E 1 Sample characteristics, language sampled, and procedure used to collect the data

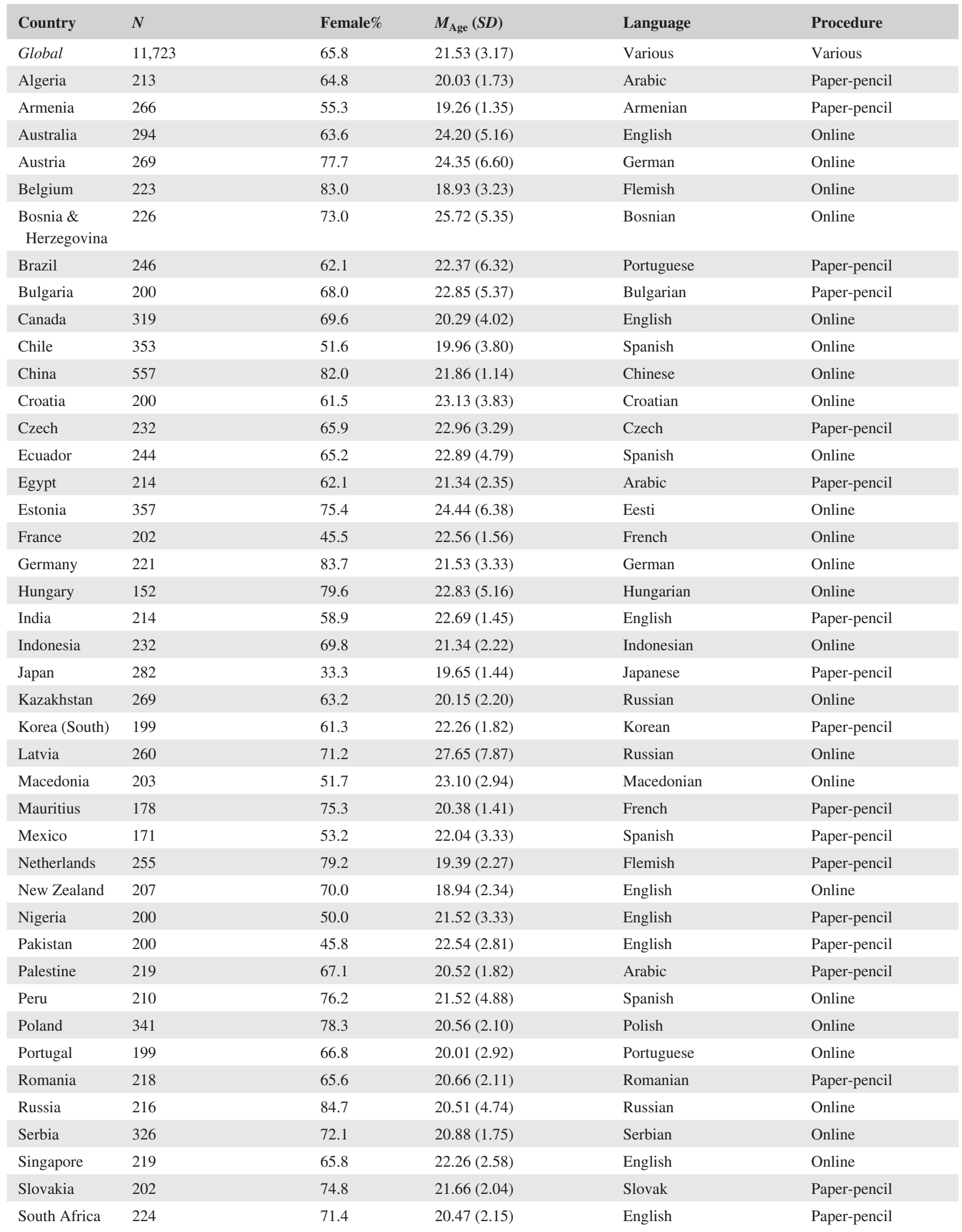


TA B L E 1 (Continued)

\begin{tabular}{|llllll}
\hline Country & $\boldsymbol{N}$ & Female $\%$ & $\boldsymbol{M}_{\text {Age }}(\boldsymbol{S D})$ & Language & Procedure \\
\hline Sweden & 212 & 72.6 & $22.79(4.36)$ & Swedish & Online \\
\hline Thailand & 177 & 76.8 & $19.61(1.37)$ & Thai & Online \\
\hline Togo & 222 & 41.4 & $20.56(2.84)$ & French & Online \\
\hline Turkey & 200 & 62.5 & $20.93(2.43)$ & Turkish & Paper-pencil \\
\hline Ukraine & 283 & 72.4 & $20.09(3.97)$ & Russian & Online \\
\hline United & 185 & 69.7 & $19.57(1.74)$ & English & Online \\
\hline Kingdom & & & & English & Online \\
\hline United States & 212 & 58.0 & $19.33(1.44)$ & \\
\hline
\end{tabular}

TA B LE 2 Invariance testing by sex and country for the Dark Triad Dirty Dozen in 49 countries

\begin{tabular}{|c|c|c|c|c|c|c|}
\hline & \multicolumn{3}{|l|}{ Sex } & \multicolumn{3}{|l|}{ Country } \\
\hline Configural & $3,205.55(102)$ & .925 & .071 & $5,845.16(2,597)$ & .933 & .074 \\
\hline Metric & $3,295.93(111)$ & .923 & .069 & $7,047.43(3,065)$ & .918 & .076 \\
\hline Scalar & $3,512(120)$ & .918 & .068 & $14,885.86(3,533)$ & .765 & .119 \\
\hline
\end{tabular}

Note.: All $\chi^{2}$ tests were significant at $p<.001$.

(i.e., Portrait Values Questionnaire or PVQ-40; Schwartz et al., 2001). Our supplementation included only three countries (Algeria, Armenia, and Kazakhstan) for which cultural values were unavailable. Although there is a notable time difference between the publication of normative cultural values data and our calculations, we note that cultural values are stable over time (Schwartz, 2008).

\section{3 | RESULTS}

Prior to hypothesis testing, we assessed the measurement invariance of the Dirty Dozen Scale across country and sex using the traditional approach of Multi-Group Confirmatory Factor Analysis (MGCFA). We found a scalar level of measurement invariance across the sexes (Table 2, left panel), allowing us to make between-sex comparisons. However, we found only metric levels of invariance across countries (Table 2, right panel). Given that scalar levels of invariance are hard to establish in large, multi-country comparisons (Davidov, Meuleman, Cieciuch, Schmidt, \& Billiet, 2014), we complemented these analyses by examining measurement invariance using the less conservative approach of alignment. Alignment allows for testing MGCFA without assuming exact measurement invariance and is based on the configural model and automatic process of detecting invariant parameters (Asparouhov \& Muthén, 2014). The alignment procedure indicated only $19 \%$ of non-invariant intercepts, which are below the critical threshold of $25 \% .^{9}$

To ensure that we could make reasonable cross-national comparisons, we tested cross-level isomorphism of the three traits via an exploratory factor analysis (EFA) with a varimax rotation. We used country-means for the Dirty Dozen items and individual data from the pooled sample. We compared country-level factor loadings to factor loadings obtained in the EFA conducted on the pooled, international sample. We obtained a three-factor solution, which explained $74.39 \%$ of the variance. We also found congruence between individual-level and country-level narcissism (Tucker's $\Phi=.96$ ), Machiavellianism $(\Phi=.94)$, and psychopathy $(\Phi=.88-$ slightly lower than the cut-off of .90).

Using meta-regression (Lipsey \& Wilson, 2001), we examined how levels of the Dark Triad traits in each country (Table 3, left panel) were related to our country-level indicators. In Table 4 (left panel), we report the standardized regression coefficients for those analyses. As expected, the country-level effects were localized to narcissism, suggesting that advanced, modern democracies had lower rates of narcissism, whereas countries with less intellectual autonomy and egalitarianism and with more hierarchy and embeddedness values had higher rates of narcissism. Machiavellian countries were likely to be characterized by low rates of gender inequality. We found no significant effects for psychopathy, and the correlation coefficients observed were notably small 
T A B L E 3 Mean-level scores for the Dark Triad Dirty Dozen traits and Cohen's $d$ for sex differences in each trait across each country

\begin{tabular}{|c|c|c|c|c|c|c|}
\hline Country & \multicolumn{3}{|l|}{ Mean $(S D)$} & \multicolumn{3}{|c|}{ Sex differences } \\
\hline Algeria & $4.11(1.67)$ & $2.33(1.45)$ & $2.39(1.37)$ & .14 & .20 & .24 \\
\hline Armenia & $4.28(1.60)$ & $3.31(1.62)$ & $2.77(1.44)$ & -.10 & .30 & .67 \\
\hline Austria & $3.27(1.37)$ & $3.23(1.52)$ & $2.63(1.23)$ & .27 & .37 & .75 \\
\hline Belgium & $3.28(1.23)$ & $3.46(1.19)$ & $2.88(1.00)$ & .42 & .53 & .85 \\
\hline $\begin{array}{l}\text { Bosnia \& } \\
\text { Herzegovina }\end{array}$ & $3.20(1.53)$ & $2.49(1.42)$ & $2.34(1.34)$ & .17 & .37 & .52 \\
\hline Chile & $3.08(1.54)$ & $3.13(1.45)$ & $2.83(1.34)$ & .44 & .43 & .51 \\
\hline China & $4.41(.98)$ & $2.83(1.07)$ & $2.55(.86)$ & .17 & .35 & .40 \\
\hline Croatia & $3.71(1.39)$ & $3.42(1.54)$ & $3.21(1.44)$ & .38 & .70 & .85 \\
\hline Czech & $3.99(1.26)$ & $3.66(1.34)$ & $2.51(1.11)$ & .05 & .42 & .71 \\
\hline Ecuador & $3.58(1.70)$ & $3.55(1.59)$ & $2.94(1.47)$ & .42 & .42 & .47 \\
\hline Egypt & $4.14(1.52)$ & $2.13(1.23)$ & $2.43(1.13)$ & .02 & .31 & .15 \\
\hline Estonia & $3.30(1.41)$ & $3.57(1.33)$ & $2.39(1.10)$ & .20 & .25 & .59 \\
\hline France & $3.83(1.29)$ & $3.73(1.35)$ & $3.12(1.43)$ & .33 & .29 & .32 \\
\hline Germany & $3.58(1.31)$ & $2.84(1.24)$ & $2.02(1.03)$ & .48 & .63 & .75 \\
\hline Korea (South) & 4.07 (1.08) & $3.23(1.14)$ & $2.86(1.14)$ & -.11 & .13 & .08 \\
\hline Latvia & $3.88(1.44)$ & $3.48(1.45)$ & $3.14(1.47)$ & .18 & .43 & .55 \\
\hline Macedonia & $3.35(1.53)$ & $2.61(1.46)$ & $2.55(1.45)$ & .26 & .53 & .36 \\
\hline Mauritius & $3.28(1.52)$ & $2.68(1.33)$ & $2.33(1.21)$ & .01 & .32 & .22 \\
\hline Mexico & $3.72(1.59)$ & $3.42(1.48)$ & $2.72(1.42)$ & .35 & .36 & .57 \\
\hline Netherlands & $3.51(1.24)$ & $3.12(1.11)$ & $3.02(.94)$ & .48 & .69 & .77 \\
\hline New Zealand & $3.55(1.22)$ & $3.46(1.26)$ & $2.64(1.22)$ & .23 & .53 & .56 \\
\hline Nigeria & $4.18(1.73)$ & $3.26(1.59)$ & $2.36(1.33)$ & .16 & .39 & .36 \\
\hline Pakistan & $4.41(1.25)$ & $3.58(1.46)$ & $3.78(1.44)$ & .24 & .38 & .52 \\
\hline Palestine & $4.21(1.51)$ & $2.41(1.36)$ & $2.48(1.09)$ & .13 & .56 & .33 \\
\hline Peru & $2.97(1.60)$ & $2.44(1.45)$ & $2.27(1.25)$ & .31 & .36 & .57 \\
\hline Poland & $3.44(1.38)$ & $2.96(1.48)$ & $2.67(1.44)$ & .38 & .26 & .11 \\
\hline Portugal & $3.03(1.14)$ & $2.06(1.02)$ & $2.07(.91)$ & .40 & .46 & .44 \\
\hline Romania & $3.29(1.45)$ & $2.94(1.48)$ & $2.64(1.32)$ & .06 & .39 & .44 \\
\hline Russia & $4.00(1.59)$ & $3.63(1.46)$ & $2.72(1.41)$ & .08 & .39 & .16 \\
\hline Serbia & $3.59(1.31)$ & $2.64(1.44)$ & $2.78(1.37)$ & .26 & .33 & .68 \\
\hline Singapore & $3.76(1.18)$ & $3.45(1.20)$ & $3.04(1.07)$ & .09 & .36 & .48 \\
\hline
\end{tabular}


TA B L E 3 (Continued)

\begin{tabular}{|c|c|c|c|c|c|c|}
\hline Country & \multicolumn{3}{|l|}{ Mean $(S D)$} & \multicolumn{3}{|c|}{ Sex differences } \\
\hline South Africa & $3.35(1.50)$ & $2.95(1.50)$ & $2.50(1.28)$ & 1.15 & 1.09 & 1.22 \\
\hline Sweden & $3.53(1.35)$ & $3.26(1.37)$ & $2.29(1.20)$ & .17 & .20 & .55 \\
\hline Turkey & $3.33(1.50)$ & $2.19(1.22)$ & $2.07(1.19)$ & .26 & .31 & .30 \\
\hline Ukraine & $3.91(1.40)$ & $3.37(1.48)$ & $2.89(1.32)$ & .62 & .67 & .51 \\
\hline United Kingdom & $2.76(1.30)$ & $2.73(1.23)$ & $2.27(1.17)$ & -.13 & .33 & .56 \\
\hline United States & $3.75(1.28)$ & $3.31(1.37)$ & $2.55(1.19)$ & .35 & .45 & .54 \\
\hline
\end{tabular}

Note.: $\mathrm{N}=$ narcissism, $\mathrm{M}=$ Machiavellianism, $\mathrm{P}=$ psychopathy. Sex scored: $1=$ male, 2 = female.

TABLE 4 The standardized regression coefficients between mean-level Dark Triad traits and the magnitude of sex differences and country-level factors

\begin{tabular}{|c|c|c|c|c|c|c|c|}
\hline \multirow{2}{*}{$\begin{array}{l}\text { Sociopolitical } \\
\text { indicators }\end{array}$} & \multirow[b]{2}{*}{$\mathbf{N}$} & \multicolumn{3}{|c|}{ Mean-levels } & \multicolumn{3}{|c|}{ Sex differences } \\
\hline & & $\mathbf{N}$ & $\mathbf{M}$ & $\mathbf{P}$ & $\mathbf{N}$ & $\mathbf{M}$ & $\mathbf{P}$ \\
\hline $\begin{array}{l}\text { Human development } \\
\text { index }\end{array}$ & 49 & $-.45^{* *}$ & .26 & -.14 & $.36^{* *}$ & .22 & $.31^{*}$ \\
\hline $\begin{array}{l}\text { Freedom from } \\
\text { corruption index }\end{array}$ & 48 & $-.39^{* * *}$ & .20 & -.09 & $.38^{* *}$ & .17 & .16 \\
\hline $\begin{array}{l}\text { Economic freedom } \\
\text { index }\end{array}$ & 48 & $-.33^{*}$ & .27 & -.11 & .20 & .15 & .19 \\
\hline Democracy index & 49 & $-.52^{* *}$ & .24 & -.07 & $.35^{* *}$ & .16 & .20 \\
\hline Global peace index ${ }^{a}$ & 49 & $.46^{* *}$ & -.13 & .09 & $-.28^{*}$ & -.11 & -.15 \\
\hline Gini index ${ }^{b}$ & 48 & .09 & -.17 & -.15 & -.13 & -.24 & $-.28^{*}$ \\
\hline $\begin{array}{l}\text { Gender inequality } \\
\text { index }^{c}\end{array}$ & 47 & $.29^{*}$ & $-.31^{*}$ & -.13 & $-.28^{*}$ & -.25 & $-.30^{*}$ \\
\hline \multicolumn{8}{|l|}{ Values } \\
\hline Embeddedness & 45 & $.42^{* *}$ & -.15 & .17 & $-.30^{*}$ & -.15 & -.23 \\
\hline Intellectual autonomy & 45 & $-.35^{*}$ & .10 & -.16 & .17 & .12 & .17 \\
\hline Affective autonomy & 45 & -.11 & .18 & .04 & .04 & .06 & .10 \\
\hline Egalitarianism & 45 & $-.45^{* *}$ & -.07 & -.18 & $.49^{* *}$ & .23 & .22 \\
\hline Hierarchy & 45 & $.39^{* *}$ & -.03 & .09 & $-.31^{*}$ & -.20 & $-.29^{*}$ \\
\hline Mastery & 45 & .05 & -.03 & .11 & -.06 & .00 & -.16 \\
\hline Harmony & 45 & -.19 & .11 & -.10 & .25 & .21 & $.33^{*}$ \\
\hline
\end{tabular}

Note.: $\mathrm{N}=$ narcissism, $\mathrm{M}=$ Machiavellianism, $\mathrm{P}=$ psychopathy.

${ }^{\mathrm{a}}$ Lower scores reflect more peaceful countries.

${ }^{b}$ Lower scores represent more equality.

${ }^{\mathrm{c}}$ Lower scores reflect less inequality.

$* p<.05 ;$

$* * p<.01$. enough to suggest that insufficient power was not a fundamental concern.

In Table 3 (right panel), we report Cohen's $d$ for sex differences in each country based on mean comparisons. Globally, men were better characterized by the Dark Triad traits than women were, with the sex difference (i.e., Cohen's d) being small for narcissism $(d=0.25)$, a little larger for Machiavellianism $(d=0.39)$, and largest for psychopathy $(d=0.47)$. Despite this, there was substantial variability in sex differences around the world. In narcissism, 
the sex difference was slightly negative in South Korea $(d=-0.11)$, and largest and positive in Germany $(d=0.48)$. In Machiavellianism, the sex difference was slightly negative in Togo $(d=-0.05)$, and largest and positive in South Africa $(d=1.09)$. In psychopathy, the sex difference was slightly negative in Japan $(d=-0.10)$, and largest and positive in South Africa $(d=1.22)$.

To understand how these sex differences systematically waxed or waned with the corresponding country-level indicators (e.g., HDI or democracy level), we again used meta-regression. Specifically, we regressed the sex differences on each country-level indicator separately with a random effects model (full information maximum likelihood estimation; Wilson, 2005). In Table 4 (right panel), we report the associations between effects for sex differences in the Dark Triad traits and our aforementioned country-level indicators. Sex differences in narcissism were larger in more affluent, stable, and democratic societies, larger in relation to sex-related egalitarianism, and larger in countries that valued embeddedness and hierarchy less and egalitarianism more. Sex differences in psychopathy were positively related to living in more gender egalitarian cultures, more developed countries, and ones characterized by less hierarchy and more harmony.
We followed up by testing the simple slopes using meta-regression in each sex to find out which sex "changed" the most in relation to the sociopolitical and cultural values (Table 5). For narcissism, the slopes ( $\beta \mathrm{s})$ were larger for women, suggesting that, as societies advance, women become especially low on narcissism; this change was weaker in men. In contrast, the correlations for Machiavellianism were similar for women and men. For psychopathy, greater inequality was linked to psychopathy in men but not in women.

\section{4 | DISCUSSION}

The dark side of personality has captured the interest of researchers and lay-people alike (Muris et al., 2017). Much of this work, however, is limited by within-country analyses and relies on relatively (by modern standards) small $(N \mathrm{~s}<300)$, W.E.I.R.D. samples. We present here the first assessment of how all three of the traits may differ in expression across 49 countries $(N=11,723)$. We attempted to understand mean-level differences and variance in sex differences as a function of a wide range of economic, political, and social factors around the world. We tested scarcity and liberalization hypotheses (Campbell \& Żemojtel-Piotrowska, 2017;

\begin{tabular}{|c|c|c|c|c|c|c|}
\hline \multirow{2}{*}{$\begin{array}{l}\text { Sociopolitical } \\
\text { indicators }\end{array}$} & \multicolumn{2}{|c|}{ Narcissism } & \multicolumn{2}{|c|}{ Machiavellianism } & \multicolumn{2}{|c|}{ Psychopathy } \\
\hline & $\mathbf{M}$ & $\mathbf{W}$ & $\mathbf{M}$ & $\mathbf{W}$ & $\mathbf{M}$ & $\mathbf{W}$ \\
\hline $\begin{array}{l}\text { Human development } \\
\text { index }\end{array}$ & $-.33^{* *}$ & $-.45^{* *}$ & $.34^{*}$ & $.33^{*}$ & .05 & -.13 \\
\hline $\begin{array}{l}\text { Freedom from } \\
\text { corruption index }\end{array}$ & -.24 & $-.38^{* *}$ & .26 & $.28^{*}$ & $<.01$ & -.04 \\
\hline $\begin{array}{l}\text { Economic freedom } \\
\text { index }\end{array}$ & -.27 & $-.31^{*}$ & $.32^{*}$ & $.32^{*}$ & $<.01$ & -.09 \\
\hline Democracy Index & $-.42^{* *}$ & $-.54^{* *}$ & $.30^{*}$ & $.28^{*}$ & .04 & -.07 \\
\hline Global peace index ${ }^{a}$ & $.38^{* *}$ & $.45^{* *}$ & -.18 & -.18 & $<.01$ & .06 \\
\hline Gini index ${ }^{\mathrm{b}}$ & .03 & .11 & -.24 & -.13 & $-.29^{*}$ & -.08 \\
\hline $\begin{array}{l}\text { Gender inequality } \\
\text { index }\end{array}$ & .18 & $.29^{*}$ & $-.39^{* *}$ & $-.36^{* *}$ & -.05 & .14 \\
\hline \multicolumn{7}{|l|}{ Values } \\
\hline Embeddedness & $.32^{*}$ & $.40^{* *}$ & -.20 & -.22 & .04 & .16 \\
\hline Intellectual autonomy & $-.29^{*}$ & $-.32^{*}$ & .15 & .15 & -.04 & -.17 \\
\hline Affective autonomy & -.12 & -.08 & .19 & .23 & .08 & .08 \\
\hline Egalitarianism & -.25 & $-.50^{* *}$ & .02 & -.05 & -.09 & -.24 \\
\hline Hierarchy & .25 & $.39^{* *}$ & -.12 & -.05 & -.08 & .16 \\
\hline Mastery & .03 & .07 & -.04 & -.04 & .02 & .15 \\
\hline $\begin{array}{l}\text { Lower scores reflect more } \mathrm{p} \\
\text { Lower scores represent mor } \\
\text { Lower scores reflect less in } \\
p<.05 \\
* *<.01 .\end{array}$ & $\begin{array}{l}\text { ceful cou } \\
\text { equality. } \\
\text { uality. }\end{array}$ & & & & & \\
\hline
\end{tabular}

TA B L E 5 Simple-slopes from metaregression between country-level rates of the dark triad traits and sociopolitical and cultural values in men (M) and women (W) 
Papageorgiou et al., 2019; Twenge \& Campbell, 2010) in relation to country-levels of the Dark Triad traits along with variance in the sex differences from country-to-country. The results were more consistent with the scarcity hypothesis. As such, the results differ from those of a previous study (Foster et al., 2003). That study, however, was based on a very small and selective number of cultures, using the forcedchoice Narcissistic Personality Inventory (NPI; Raskin \& Terry, 1988) as a measure of narcissism. Also, these authors did not report scalar measurement invariance. However, recent work suggests caution against comparison on the forced-choice NPI that involves a few countries (ŻemojtelPiotrowska et al., 2018). Here, we used a different measure of grandiose narcissism (with responses ranging on a continuum rather than being forced-choice), sampled a wide array of cultures, and obtained scalar measurement invariance. Thus, we have confidence in the validity of our findings.

Of course, countries are likely to differ in how narcissistic, psychopathic, and Machiavellian their populations are. But, is this variability meaningful or just noise created by psychometric issues in cross-cultural psychology? Our findings point to systematic trends in how country-level rates of the Dark Triad traits—narcissism in particular-are sensitive to country-level features around social, political, and economic development as well as cultural values. The less developed, less free, more corrupt, less peaceful, and more sex-asymmetrical a country is, the more narcissistic its population is. These results converge on the scarcity hypothesis and align with predictions from evolutionary psychology. Narcissism is likely an adaptation to enable people to compete for limited resources in competitive environments (Jonason et al., 2019).

Narcissism is reliably linked to competitiveness, agency, and individualism (Jonason et al., 2017; Roberts, Woodman, $\&$ Sedikides, 2018). These dispositional features are typically considered evidence of the pathological nature of narcissism. Instead, narcissism may be a pseudo-pathology, whereby it benefits the individual at the cost of the group, and is only called a pathology because of the externalities imposed on the group (Crawford \& Anderson, 1989). In accord with that view, countries that value embeddedness and hierarchy, but do not value egalitarianism and intellectual autonomy, had a more narcissistic population. That is, countries that value social connection, competitiveness, and status differences have citizens who are more narcissistic. These cultural values resemble a ratcheting-up of individual values to the country-level. For example, narcissism, unlike the other Dark Triad traits, is correlated with a desire for social connection (Twenge \& Campbell, 2010). Given so, we expected and found that narcissism was the most sensitive of the three Dark Triad traits to socioecological variance at the country-level.

Machiavellianism and psychopathy rates at the country-level were rather insensitive to the country features and values that we chose to examine, with one exception.
Countries that were more Machiavellian were also more advanced on gender equality. In the case of Machiavellianism (not psychopathy), several correlations with sociopolitical factors (but not values) were larger than the average correlation in social and personality psychology over the last 100 years (i.e., $r \approx .20$; Richard et al., 2003). This suggests that limited statistical power in the cross-national tests might have obscured associations for Machiavellianism (but not psychopathy). Indeed, the pattern indicates something distinct from narcissism. As societies become more advanced, citizens become more Machiavellian. In countries farther from the equator-countries that are typically more sociopolitically advanced like Sweden or Norway-there are higher rates of Machiavellianism and lower rates of narcissism (Jonason \& Schmitt, 2017). We conjecture that more advanced societies have more "checks" on people's antisocial behavior, which forces those intent on deception to adopt subtler and longer-term forms of manipulation. Indeed, Niccolò Machiavelli (2010) wrote during a time of relative political and economic sophistication and was focused on mentoring young nobles on maneuvering the complicated political landscape to achieve lasting power (Jones, 2016). ${ }^{10}$

We also documented substantial variance in the magnitude of sex differences in the Dark Triad traits. Superficially, this might appear to refute evolutionary models of sex differences. That is, some critics of evolutionary psychology might contend that sex differences must be the same from country-to-country (i.e., universally invariant) for them to be evidence of a species-level adaptation. However, if one considers evolutionary psychology an interactionist paradigm, it suggests that differences in the sexes in personality are facultatively calibrated to local conditions (Buss, 2009; Crawford $\&$ Anderson, 1989). We found that sex differences in narcissism were larger in "safer" (e.g., affluent, stable), westernized (i.e., democratic), and liberal (i.e., egalitarianism) countries.

Importantly, this general pattern hints that in more modern societies, sex differences are larger, as women in such societies were especially low in narcissism. Keeping in mind the scarcity hypothesis, this might be because women in modern societies are freed from the need to be highly selfish and agentic. Narcissism, in women living in harsher cultures, may help to augment access to resources that their mates and societies fail to provide. Modern women need more resources than men do, given the role they play as child-bearers and child-rearers-a pattern that is likely phylogenetic inertia from ancestral women facing such challenges. Our results are consistent with work on the Big Five traits (Giolla \& Kajonius, 2019), narcissism as measured with the NPI-40 (Schmitt, Alcalay, et al., 2017), and preferences for risk (Falk $\&$ Hermle, 2018).

These sex difference patterns are more consistent with evolutionary models of personality than social role theories. Social role theories predict the opposite pattern than the one 
we obtained (i.e., that sex differences in narcissism would be larger in countries that are less, not more advanced). In addition, there were no sex differences in Machiavellianism and several for psychopathy. Sex differences in psychopathy were larger in countries that had less gender inequality, more equality overall, a greater focus on hierarchy, and more harmony. For example, in the case of general inequality, men were more psychopathic in countries that were more equal. Collectively, this might imply a specific niche that best allows psychopaths - who tend to be men - to exploit others, a niche that is competitive economically, but also values people getting along. In more advanced societies, with weaker ties among people, psychopathy in men might be able to flourish. However, in less advanced societies, people know each other and have more face-to-face interactions allowing for the detection of men who engage in psychopathic behaviors. Indeed, psychopathy is linked to preferences for the relatively impersonal living conditions where competition is strong in the form of modern cities (Jonason, 2018).

\section{1 | Limitations}

Despite the novelty, the large, multinational sample, and the integration of country-level and individual-level data, our study has several limitations. To begin, although our data are not strictly W.E.I.R.D. (Henrich et al., 2010), they may still be subject to sampling biases, given our reliance on convenience samples of students living in relatively stable environments. Future research should expand the socioeconomic and linguistic range of the data we collected to verify that these effects generalize more widely, ideally with representative samples in each country.

Also, we acknowledge the subjectivity involved in the selection of cultural and economic indices that we used to test our hypotheses. Although there are other prominent cross-cultural theories, such as the GLOBE project (House, Hanges, Javidan, Dorfman, \& Gupta, 2004) and Hofstede, Hofstede, and Minkov (2010) cultural dimensions, we opted for Schwartzian cultural values. These are correlated with individual-level values (Smith, Peterson, \& Schwartz, 2002), which in turn are correlated with the Dark Triad traits (Kajonius, Persson, \& Jonason, 2015). However, further research could extend our findings by searching for additional cultural factors responsible for cultural variance of the Dark Triad. Indeed, we have reported a substantial array of basic details here, allowing the interested researcher to take these details, pair them with the country-level factors in which they are interested and conduct relevant analyses. We encourage such work whether it be independent or in collaboration with us.

Moreover, our study was cross-sectional. Hence, we cannot track changes over time in the Dark Triad traits, claim that the country-level effects cause the traits or the sex differences to vary, or there is not a mere scaling-up from individual to country in the effects. Future work could manipulate cues to the liberalization and scarcity to provide a more refined test of our hypotheses.

Furthermore, there is no shortage of criticism for the Dirty Dozen as a measure of the Dark Triad traits (Maples, Lamkin, $\&$ Miller, 2014). Our adoption of this measure was guided by an objective for measurement efficiency and for minimizing translation efforts in this large, multi-lab, multi-country project. In related research, drawing on these data, we found satisfactory levels of measurement invariance, allowing us to make reliable cross-cultural comparisons (Rogoza et al., 2020), and our isomorphism tests support this conclusion. The Dirty Dozen measure of narcissism, for example, may capture better vulnerable than grandiose narcissism, but the current results are consistent with work using other measures of narcissism (Jonason et al., 2019; Schmitt, Alcalay, et al., 2017). Above measurement concerns, there are doubts about whether Machiavellianism is redundant to psychopathy (Miller, Hyatt, Maples-Keller, Carter, \& Lynam, 2017; see also: Vize, Collison, Miller, \& Lynam, 2018; Vize, Lynam, Collison, \& Miller, 2018). Our results suggest different effects for these two traits. Nevertheless, follow-up investigations could use lengthier assessments of the three traits to capture a more nuanced and potentially accurate view of cross-cultural variance in the Dark Triad traits.

Lastly, we failed to incorporate other potentially interesting "dark" personality traits, like sadism or spitefulness (Buckels, Jones, \& Paulhus, 2013; Marcus, Zeigler-Hill, Mercer, \& Norris, 2014). However, there is some doubt about the utility-incremental validity-of their inclusion. Nevertheless, we encourage future research to capture a wider array of "dark" personality traits, given the deleterious externalities these traits have on the world.

\section{5 | CONCLUSION}

We provided the first systematic and wide-scale examination of cross-cultural variance in the Dark Triad traits. Narcissistic countries (if there is such a thing; Johnson, 2020) appear to be less advanced, consistent with the scarcity hypothesis, and sex differences in narcissism appear larger in more advanced places, mostly as a function of a diminishing return on being narcissistic provided for women in these modern places. Although sex differences in Machiavellianism rates were insensitive to country-level factors, there were hints that more advanced places were more Machiavellian, a finding that supports a liberalization hypothesis. Also, although psychopathy rates were insensitive to country-level, sex differences were larger where there was more inequality. In closing, we offered a robust 
accounting of how countries differ in how much their populations - women and men-are characterized by the Dark Triad traits.

\section{ACKNOWLEDGMENTS}

We thank Jeremy Frimer for providing the Canadian sample, Shalom H. Schwartz for commenting our paper prior to submission, and Radosław Rogoza for statistical consultation regarding cross-cultural invariance.

The authors disclosed receipt of the following financial support for the research, authorship, and/or publication of this article: Peter Jonason was partially funded by a grant from the Polish National Agency for Academic Exchange (PPN/ULM/2019/1/00019/U/00001). Magdalena ŻemojtelPiotrowska and Jarosław Piotrowski were supported by a grant from the Polish National Science Centre (2016/21/B/ HS6/01069). Kokou A. Atitsogbe was supported by a Swiss Government Excellence PhD Scholarship no. 2015.0639/ Togo/OP. Valdiney V. Gouveia was supported by the Brazilian National Council of Technological and Scientific Development. Joel Gruneau Brulin was supported by a John Templeton Foundation grant (51897). Martina KlicperovaBaker was supported by grants from the Grant Agency of the Czech Republic (\#15-11062S) and the Czech Academy of Sciences (RVO 68081740). Evgeny Osin was supported by a grant from the Russian Academic Excellence (5-100).

\section{CONFLICT OF INTEREST}

The authors declared no potential conflicts of interest with respect to the research, authorship, and/or publication of this article.

\section{ORCID}

Peter K. Jonason (iD https://orcid. org/0000-0002-8833-048X

Magdalena Żemojtel-Piotrowska iD https://orcid. org/0000-0002-8017-8014

John Maltby iD https://orcid.org/0000-0002-0621-9359

\section{ENDNOTES}

${ }^{1}$ A full list of scales included in this larger project can be found at www.crossculturalpsychlab.com.

${ }^{2}$ In all 49 countries, Machiavellianism was correlated with psychopathy (ranging from $r[231]=.37, p<.001$ in Czech Republic to $r[202]=.80, p<.001$ in North Macedonia) and narcissism (ranging from $r[221]=.18, p<.05$ in Togo to $r[201]=.66, p<.001$ in Slovakia), and psychopathy was correlated with narcissism (ranging from $r[556]=.13, p<.05$ in China to $r[201]=.69$, $p<.001$ in Slovakia). Country-level narcissism was correlated with country-level Machiavellianism $(r[48]=.25, p<.05)$ and with country-level psychopathy $(r[48]=.45, p<.01)$. Countrylevel Machiavellianism and country-level psychopathy were also correlated $(r[48]=.58, p<.01)$.

${ }^{3}$ hdr.undp.org/en/content/human-development-index-hdi
${ }^{4}$ www.eiu.com/topic/democracy-index

5 www.heritage.org/index/

${ }^{6}$ hdr.undp.org/en/content/gender-inequality-index-gii

${ }^{7}$ reliefweb.int/report/world/global-peace-index-2018

${ }^{8}$ https://www.cia.gov/library/publications/the-world-factbook

${ }^{9}$ If less than $25 \%$ of the intercepts are non-invariant, there is sufficient scalar invariance to consider cross-cultural comparisons as trustworthy (Asparouhov \& Muthén, 2014).

${ }^{10}$ Niccolò Machiavelli may also intended to warn subtly the populace about the dangers associated with a Machiavellian leader.

\section{REFERENCES}

Asparouhov, T., \& Muthén, B. O. (2014). Multi-group factor analysis alignment. Structural Equation Modeling, 21, 1-14. https://doi. org/10.1080/10705511.2014.919210

Buckels, E. E., Jones, D. N., \& Paulhus, D. L. (2013). Behavioral confirmation of everyday sadism. Psychological Science, 24, 2201-2209. https://doi.org/10.1177/0956797613490749

Buss, D. M. (2009). How can evolutionary psychology explain personality and individual differences? Perspectives on Psychological Science, 4, 359-366. https://doi.org/10.1111/j.1745-6924.2009.01138.x

Campbell, W. K., \& Żemojtel-Piotrowska, M. (2017). Psychological entitlement across 50 countries: Invariance, isomorphism and theoretically relevant correlates. Paper presented at the regional meeting of International Association of Cross-Cultural Psychology, Warsaw.

Carter, G. L., Lyons, M., \& Brewer, G. (2018). Lifetime offspring and the Dark Triad. Personality and Individual Differences, 132, 79-83. https://doi.org/10.1016/j.paid.2018.05.017

Crawford, C. B., \& Anderson, J. L. (1989). Sociobiology: An environmentalist discipline. American Psychologist, 44, 1449-1459. https:// doi.org/10.1037/0003-066X.44.12.1449

Davidov, E., Meuleman, B., Cieciuch, J., Schmidt, P., \& Billiet, J. (2014). Measurement equivalence in cross-national research. Annual Review of Sociology, 40, 55-75. https://doi.org/10.1146/ annurev-soc-071913-043137

Eagly, A. H., \& Wood, W. (1999). The origins of sex differences in human behavior: Evolved dispositions versus social roles. American Psychologist, 54, 408-423. https://doi. org/10.1037//0003-066x.54.6.408

Falk, A., \& Hermle, J. (2018). Relationship of gender differences in preferences to economic development and gender equality. Science, 362, eaas9899. https://doi.org/10.1126/science.aas9899

Figueredo, A. J., Wolf, P. S. A., Gladden, P. R., Olderbak, S. D., Andrzejczak, D. J., \& Jacobs, W. J. (2009). Ecological approaches to personality. In D. M. Buss \& P. Hawley (Eds.), The evolution of personality and individual differences. New York, NY: Oxford University Press.

Foster, J. D., Campbell, W. K., \& Twenge, J. M. (2003). Individual differences in narcissism: Inflated self-views across the lifespan and around the world. Journal of Research in Personality, 37(6), 469486. https://doi.org/10.1016/S0092-6566(03)00026-6

Gebauer, J. E., \& Sedikides, C. (2018). Agency and communion in grandiose narcissism. In A. E. Abele \& B. Wojciszke (Eds.), Agency and communion in social psychology (pp. 90-102). Abingdon-onThames, UK: Routledge.

Giolla, E. M., \& Kajonius, P. J. (2019). Sex differences in personality are larger in gender equal countries: Replicating and extending a 
surprising finding. International Journal of Psychology, 54, 705711. https://doi.org/10.1002/ijop.12529

Henrich, J., Heine, S., \& Norenzayan, A. (2010). The WEIRDest people of the world? Behavioral and Brain Sciences, 33, 61-135. https:// doi.org/10.1017/S0140525X0999152X

Hofstede, G., Hofstede, G. J., \& Minkov, M. (2010). Cultures and organizations: Software of the mind. New York, NY: McGraw-Hill.

House, R. J., Hanges, P. J., Javidan, M., Dorfman, P. W., \& Gupta, V. (2004). Culture, leadership, and organizations: The GLOBE study of 62 societies. New York, NY: Sage.

Inglehart, R., Basanez, M., Diez-Madrano, J., Halman, L., \& Luijkx, R. (2004). Human beliefs and values: A cross cultural source book based on the 1999-2002 values surveys. Mexico: Siglio XXI Editores.

Inglehart, R., \& Norris, P. (2009). Rising tide: Gender equality and cultural change across world. Cambridge, UK: Cambridge University Press.

Johnson, L. K. (2020). Narcissistic people, not narcissistic nations: Using multilevel modelling to explore narcissism across countries. Personality and Individual Differences, 163, 110079. https://doi. org/10.1016/j.paid.2020.110079

Jonason, P. K. (2018). Bright lights, big city: The Dark Triad traits and geographical preferences. Personality and Individual Differences, 132, 66-73. https://doi.org/10.1016/j.paid.2018.05.024

Jonason, P. K., Foster, J. D., Oshio, A., Sitnikova, M., Birkas, B., \& Gouveia, V. V. (2017). Self-construals and the Dark Triad traits in six countries. Personality and Individual Differences, 113, 120-124. https://doi.org/10.1016/j.paid.2017.02.053

Jonason, P. K., Li, N. P., \& Czarna, A. Z. (2013). Quick and Dirty: Some psychosocial costs associated with the Dark Triad in three countries. Evolutionary Psychology, 11, 172-185. https://doi. org/10.1177/147470491301100116

Jonason, P. K., Okan, C., \& Özsoy, E. (2019). The Dark Triad traits in Australia and Turkey. Personality and Individual Differences, 149, 123-127. https://doi.org/10.1016/j.paid.2019.05.058

Jonason, P. K., \& Schmitt, D. P. (2017). Where the psychological adaptations hit the ecological road. Behavioral and Brain Sciences, 40, 23-25. https://doi.org/10.1017/S0140525X16001199

Jonason, P. K., \& Webster, G. D. (2010). The Dirty Dozen: A concise measure of the Dark Triad. Psychological Assessment, 22, 420-432. https://doi.org/10.1037/a0019265

Jones, D. N. (2016). The nature of Machiavellianism: Distinct patterns of misbehavior. In V. Zeigler-Hill \& D. K. Marcus (Eds.), The dark side of personality: Science and practice in social, personality, and clinical psychology (pp. 87-107). Washington, DC: American Psychological Association.

Kajonius, P., Persson, B., \& Jonason, P. K. (2015). Hedonism, achievement, and power: Universal values that characterize the Dark Triad. Personality and Individual Differences, 77, 173-178. https://doi. org/10.1016/j.paid.2014.12.055

Kenrick, D. T., Sadalla, E. K., Groth, G., \& Trost, M. R. (1990). Evolution, traits, and the stages of human courtship: Qualifying the parental investment model. Journal of Personality, 58, 97-116. https://doi.org/10.1111/j.1467-6494.1990.tb00909.x

Leung, K., \& Bond, M. H. (2004). Social axioms: A model for social beliefs in multi-cultural perspective. Advances in Experimental Social Psychology, 36, 122-197. https://doi.org/10.1016/S0065 -2601(04)36003-X

Lipsey, M. W., \& Wilson, D. B. (2001). Practical meta-analysis. Thousand Oaks, CA: Sage.
Machiavelli, N. (2010). The prince (2nd ed.). Chicago, IL: University of Chicago Press. (Original work published 1532)

Mahadevan, N., Gregg, A. P., \& Sedikides, C. (2019). Is self-regard a sociometer or a hierometer? Self-esteem tracks status and inclusion, narcissism tracks status. Journal of Personality and Social Psychology, 116, 444-466. https://doi.org/10.1037/pspp0000189

Maples, J. L., Lamkin, J., \& Miller, J. D. (2014). A test of two brief measures of the Dark Triad: The Dirty Dozen and Short Dark Triad. Psychological Assessment, 26, 326-331. https://doi.org/10.1037/ a0035084

Marcus, D. K., Zeigler-Hill, V., Mercer, S. H., \& Norris, A. L. (2014). The psychology of spite and the measurement of spitefulness. Psychological Assessment, 26, 563-574. https://doi.org/10.1037/ a0036039

Miller, J. D., Hyatt, C. S., Maples-Keller, J. L., Carter, N. T., \& Lynam, D. R. (2017). Psychopathy and Machiavellianism: A distinction without a difference? Journal of Personality, 85(638), 439-453. https://doi.org/10.1111/jopy.12251

Miller, J. D., Maples, J. L., Buffardi, L., Cai, H., Gentile, B., KisbuSakarya, Y., ... Campbell, W. K. (2015). Narcissism and United States' culture: The view from home and around the world. Journal of Personality and Social Psychology, 109, 1068-1089. https://doi. org/10.1037/a0039543

Muris, P., Merckelbach, H., Otgaar, H., \& Meijer, E. (2017). The malevolent side of human nature: A meta-analysis and critical review of the literature on the Dark Triad (narcissism, Machiavellianism, and psychopathy). Perspectives on Psychological Science, 12, 183-204. https://doi.org/10.1177/1745691616666070

Neumann, C., Schmitt, D. P., Carter, R., Embley, I., \& Hare, R. D. (2012). Psychopathic traits in males and females across the globe. Behavioral Sciences \& the Law, 30, 557-574. https://doi. org/10.1037/ebs0000065

Papageorgiou, K. A., Gianniou, F.-M., Wilson, P., Moneta, G. B., Bilello, D., \& Clough, P. J. (2019). The bright side of dark: Exploring the positive effect of narcissism on perceived stress through mental toughness. Personality and Individual Differences, 139, 116-124. https://doi.org/10.1016/j.paid.2018.11.004

Raskin, R., \& Terry, H. (1988). A principal-components analysis of the Narcissistic Personality Inventory and further evidence of its construct validity. Journal of Personality and Social Psychology, 54, 890-902. https://doi.org/10.1037/0022-3514.54.5.890

Richard, F. D., Bond, C. F., Jr., \& Stokes-Zoota, J. J. (2003). One hundred years of social psychology quantitatively described. Review of General Psychology, 7, 331-363. https://doi. org/10.1037/1089-2680.7.4.331

Roberts, T., Woodman, T., \& Sedikides, C. (2018). Pass me the ball: Narcissism in performance settings. International Review of Sport and Exercise Psychology, 11, 190-213. https://doi. org/10.1080/1750984X.2017.1290815

Rogoza, R., Żemojtel-Piotrowska, M., Jonason, P. K., Piotrowski, J., Campbell, W. K., Gebauer, J. E., ... Wlodarczyk, A. (2020). Structure of the Dark Triad: Evidence from 49 countries. Assessment. Advance online publication. https://doi.org/10.1177/1073191120922611

Różycka-Tran, J., Boski, P., \& Wojciszke, B. (2015). Belief in zero-sum game as social axiom: A 37-nation study. Journal of Cross-Cultural Psychology, 46, 525-548. https://doi.org/10.1177/0022022115 572226

Różycka-Tran, J., Jurek, P., Olech, M., Piotrowski, J., \& ŻemojtelPiotrowska, M. (2019). A warrior society: Data from 30 countries show that belief in life as a zero-sum game is related to military 
expenditure and low civic liberties. Frontiers in Psychology, 9, 2645. https://doi.org/10.3389/fpsyg.2018.02645

Schmitt, D. P., Alcalay, L., Allik, J., Alves, I. C. B., Anderson, C. A., Angelini, A. L., ... Kökény, T. (2017). Narcissism and the strategic pursuit of short-term mating: Universal links across 11 world regions of the International Sexuality Description Project-2. Psihologijske Teme, 26, 89-137.

Schmitt, D. P., Long, A. E., McPhearson, A., O'Brien, K., Remmert, B., \& Shah, S. H. (2017). Personality and gender differences in global perspective. International Journal of Psychology, 52(Suppl. 1), 4556. https://doi.org/10.1002/ijop.12265

Schwartz, S. H. (2008). Cultural value orientations: Nature and implications of national differences. Moscow, Russia: State University Higher School of Economics Press.

Schwartz, S. H., Melech, G., Lehmann, A., Burgess, S., Harris, M., \& Owens, V. (2001). Extending the cross-cultural validity of the theory of basic human values with a different method of measurement. Journal of Cross-Cultural Psychology, 32(5), 519-542. https://doi. org/10.1177/0022022101032005001

Sedikides, C., \& Campbell, W. K. (2017). Narcissistic force meets systemic resistance: The Energy Clash Model. Perspectives on Psychological Science, 12, 400-421. https://doi.org/10.1177/17456 91617692105

Smith, P. B., Peterson, M. F., \& Schwartz, S. H. (2002). Cultural values, sources of guidance, and their relevance to managerial behavior: A 47-nation study. Journal of Cross-Cultural Psychology, 33, 188-208. https://doi.org/10.1177/0022022102033002005

Thomaes, S., Brummelman, E., \& Sedikides, C. (2018). Narcissism: A social-developmental perspective. In V. Zeigler-Hill \& T. K. Shackelford (Eds.), The SAGE handbook of personality and individual differences (pp. 377-396). Thousand Oaks, CA: Sage.

Twenge, J., \& Campbell, W. K. (2010). Narcissistic epidemic: Living in the age of entitlement. New York, NY: ATRIA books.
Vernon, P. A., Villani, V. C., Vickers, L. C., \& Harris, J. A. (2008). A behavioral genetics investigation of the Dark Triad and the Big 5. Personality and Individual Differences, 44, 445-452. https://doi. org/10.1016/j.paid.2007.09.007

Vize, C. E., Collison, K. L., Miller, J. D., \& Lynam, D. R. (2018). Examining the effects of controlling for shared variance among the Dark Triad using meta-analytic structural equation modelling. European Journal of Personality, 32(1), 46-61. https://doi.org/10.1002/per.2137

Vize, C. E., Lynam, D. R., Collison, K. L., \& Miller, J. D. (2018). Differences among Dark Triad components: A meta-analytic investigation. Personality Disorders: Theory, Research, and Treatment, 9(2), 101-111. https://doi.org/10.1037/per0000222

Wilson, D. B. (2005). Meta-analysis macros for SAS, SPSS, and Stata. Retrieved from http://mason.gmu.edu/ dwilsonb/ma.html

Żemojtel-Piotrowska, M., Piotrowski, J., Cieciuch, J., Chargazia, M., Halik, M. J., Ilisko, D., ...Truong, K. H. (2014). The structure and measurement equivalence for new Schwartz's values measured by classic PVQ-40 in 28 Nations. Congress of International CrossCultural Psychology Association, Reims, France, 16-21 July 2014.

Żemojtel-Piotrowska, M., Piotrowski, J., Rogoza, R., Hitokoto, H., Baran, T., \& Maltby, J. (2018). Cross-cultural invariance of NPI-13: Entitlement as culturally specific, leadership and grandiosity as culturally universal. International Journal of Psychology, 54, 439-447. https://doi.org/10.1002/ijop.12487

How to cite this article: Jonason PK, ŻemojtelPiotrowska M, Piotrowski J, et al. Country-level correlates of the Dark Triad traits in 49 countries. J Pers. 2020;88:1252-1267. https://doi.org/10.1111/ jopy. 12569 